\title{
SYNTHESIS OF A HIGH-PERFORMANCE ANTIMICROBIAL O-QUATERNIZED ALGINATE - A PROMISING POTENTIAL
} ANTIMICROBIAL AGENT

\author{
MAHMOUD H. ABU ELELLA, ${ }^{*}$ MARWA M. ABDEL-AZIZ** and NAHED A. ABD EL-GHANY* \\ "Chemistry Department, Faculty of Science, Cairo University, Giza, 12613, Egypt \\ *** Regional Center for Mycology and Biotechnology, Al-Azhar University, Cairo, 11651, Egypt \\ \Corresponding author: N.A.Abd El-Ghany,dr_nahed_055@yahoo.com
}

Received October 1, 2020

Three novel biologically active quaternized sodium alginates were synthesized via the reaction of sodium alginate (SA) with 3-chloro-2-hydroxypropyl trimethylammonium chloride, at room temperature for different time intervals (1, 3 and $6 \mathrm{~h}$ ), to produce quaternized sodium alginates designated as QSA1, QSA3 and QSA6. The percentage degree of quaternization (DQ\%) significantly increased with increasing the reaction time. Images from FTIR, ${ }^{1} \mathrm{H}-\mathrm{NMR}, \mathrm{XRD}$ and SEM have confirmed the chemical structures of the QSA samples. Their antimicrobial activity was investigated against bacteria and fungi using XTT assay, and the results showed that all QSA samples displayed high growth inhibition capacity of the tested microorganisms, compared to zero inhibition for SA, as shown by their lower minimum inhibitory concentration (MIC). The QSA6 was the best antimicrobial composite, displaying the same MIC value as that of the used reference drugs. The developed composites were found to be safe on normal human fibroblast cells (WI-38 cell line), by evaluating them using cytotoxic activity measurement, which makes QSA a promising material in biomedical and food applications.

Keywords: quaternized sodium alginate, Quat188, antimicrobial activity, XTT assay, cytotoxicity

\section{INTRODUCTION}

Microbial infection is considered as one of the most serious problems that threaten millions of people worldwide. It is caused by pathogenic microorganisms as Staphylococcus aureus, Pseudomonas aeruginosa and Salmonella enteritidis as bacteria and Aspergillus niger as a fungus, leading to different illnesses, such as nausea, pneumonia, abdominal pain, enterocolitis, pyogenic liver abscess, hemorrhagic colitis, diarrhea, hemolytic uremic syndrome and vomiting. Consequently, on a global level, researchers have been doing their best to develop new effective antimicrobial systems. ${ }^{1-5}$ In view of their important, effective and broad-spectrum activity against resistant microorganisms, polymers have recently attracted great interest. ${ }^{6-9}$ In addition, antimicrobial polymers may be used in comprehensive preservation and packaging of food, and in the textile industry. ${ }^{10,11}$ Consequently, the development of antimicrobial polymers is one of the main areas of antimicrobial drug delivery research with the objective to control microbial infection in biomedical devices, ${ }^{12}$ wound healing, ${ }^{13}$ food packaging, ${ }^{14}$ textiles, cosmetics products ${ }^{15}$ and water treatment systems. ${ }^{16}$

Due to their excellent properties, polysaccharides have been commonly used in a wide range of applications in the biomedical and food industries, as they have biocompatibility, biodegradability, low cost, and non-toxicity to human cells. ${ }^{17}$ Among polysaccharides, alginates have attracted considerable interest in the development of biopolymers, because they represent sustainable polymers present in the brown algae (Phaeophyceae) cell walls. ${ }^{18}$

Alginate is a linear anionic polysaccharide composed of $\beta$-D-mannuronate and $\alpha$-Lguluronate connected by glycosidic bonds $(1,4)$. It is not intrinsically antimicrobial in nature and thus most work related to the use of alginatebased materials with antibacterial properties depends on the incorporation of antibiotic segments into the alginate matrix, either 
chemically by the grafting technique, or physically by ionic interaction. ${ }^{19}$

It is well known that quaternary ammonium salts are cationic compounds that contain alkyl groups and have a strong antimicrobial activity, 23 primarily due to their ability to promote ionic exchange between the membrane cell and the positively charged species, resulting in microbial cell membrane damage, resulting in intracellular components leakage and cell death. Polysaccharides as chitosan, ${ }^{24}$ cellulose $^{25}$ and starch, ${ }^{26}$ have been quaternized with N-(3-chloro2-hydroxypropyl) trimethylammonium chloride and other quaternized agents to produce quaternized materials with strong antimicrobial activity, which have been used in numerous biomedical and food applications. ${ }^{27-29}$ Furthermore, sodium alginate was blended with quaternized

Ncarboxymethylpyridine), ${ }^{30}$ quaternized carboxymethyl chitosan/clay nanocomposite ${ }^{31}$ and quaternized chitosan; the blending process greatly improved the physical, chemical and antimicrobial properties of alginate. No studies have been made on direct quaternization of alginate via introducing the quaternary ammonium group on the alginate backbone so far.

Therefore, in the present study, our aim was to prepare quaternized sodium alginates (QSAs) via the reaction of sodium alginate with $\mathrm{N}$-(3-chloro2-hydroxypropyl) trimethylammonium chloride at room temperature to be used as active antimicrobial agents. The chemical structures of the prepared QSAs were verified by FTIR, 1HNMR, SEM, and XRD analysis. The effect of changing the reaction time on the degree of quaternization (DQ\%) was studied. In addition, the antimicrobial activities of the prepared QSAs were examined against various pathogenic microorganisms: Staphylococcus aureus (S. aureus) as a Gram-positive bacterium, Pseudomonas aeruginosa (P. aeruginosa) and Salmonella enteritidis ( $S$. enteritidis) as Gramnegative bacteria, and Aspergillus niger (A. niger) as a fungus. The cytotoxicity of the modified alginate on the human cell line was also evaluated.

\section{EXPERIMENTAL}

\section{Materials}

Sodium alginate (SA) was purchased from AlphaChemika (India). Quaternary ammonium salt, Quat 188, (N-3-chloro-2-hydroxypropyl-trimethyl ammonium chloride solution, $60 \mathrm{wt} \%$ in $\mathrm{H}_{2} \mathrm{O}$ ) was supplied from Sigma-Aldrich, Germany. We purchased regenerated cellophane dialysis tubes, with molecular weight cut off $12-14 \times 10^{3} \mathrm{~g} \mathrm{~mol}^{-1}$ from Serva Electrophoresis, Heidelberg, Germany. The tested pathogens: Staphylococcus aureus (ATCC 25923) as a Gram-positive bacterium, Pseudomonas aeruginosa (ATCC 15692) and Salmonella enteritidis (ATCC 13076) as Gram-negative bacteria, and Aspergillus niger (ATCC 9142) as a fungus, were supplied by Regional Center for Mycology and Biotechnology of Azhar University, Egypt.

\section{Methods}

Synthesis of O-quaternized sodium alginate (QSA)

A predetermined amount of $1 \mathrm{~g}$ of SA $(0.005 \mathrm{~mol})$ was dissolved in $10 \mathrm{~mL}$ of distilled water and the $\mathrm{pH}$ of the solution was adjusted to 11 with $1 \mathrm{M} \mathrm{NaOH}$. An equal weight ratio $(0.005 \mathrm{~mol})$ of $\mathrm{N}$-(3-chloro-2hydroxypropyl) trimethylammonium chloride (Quat188) was gradually added to the above solution. The $\mathrm{pH}$ of the solution changed to 8 after the addition of Quat188. The mixture was well stirred under nitrogen atmosphere at $70{ }^{\circ} \mathrm{C}$ for different periods of time: 1, 3 and $6 \mathrm{~h}$ (Scheme 1).

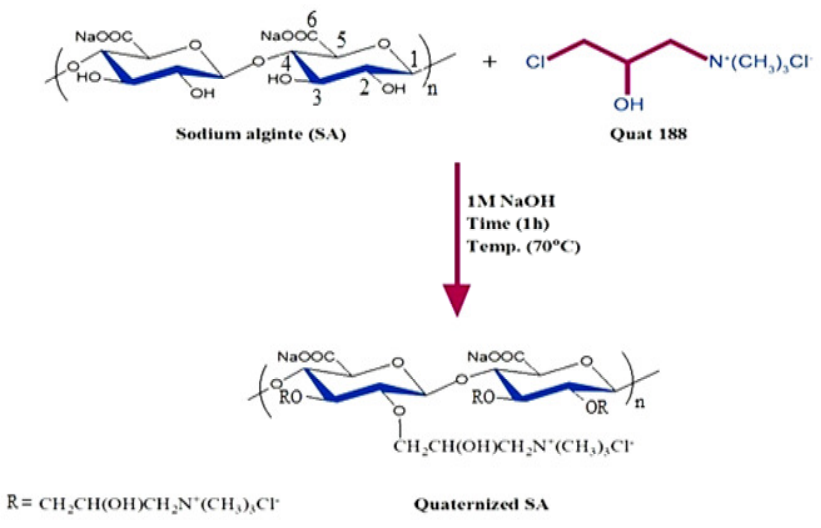

Scheme 1: Synthesis of quaternized sodium alginate composite (QSA) 
After the mentioned time, the solution was neutralized by $1 \mathrm{M} \mathrm{HCl}$. The product was purified using a dialysis membrane against distilled water for three days, in which, water was changed once daily. After three days, the resulted product was precipitated with cold ethanol and collected by centrifugation (3,000 rpm for $10 \mathrm{~min}$ ) and then drying at $60{ }^{\circ} \mathrm{C}$ to constant weight. Finally, the degree of quaternization on SA chains was calculated from $1 \mathrm{H}-\mathrm{NMR}$ spectroscopy. ${ }^{32}$

\section{XTT assay for determination of minimum inhibitory concentration (MIC) \\ Minimum inhibitory concentration is known as the} lowest antimicrobial agent concentration that inhibits a microorganism's growth during overnight incubation. The MIC of all grafted samples was determined by XTT assay (Cell Proliferation Kit II), using a microdilution method previously mentioned by Tunney et al., ${ }^{33}$ against different pathogenic microorganisms, namely Staphylococcus aureus (S. aureus) as Grampositive bacteria, Pseudomonas aeruginosa ( $P$. aeruginosa) and Salmonella enteritidis ( $S$. enteritidis) as Gram-negative bacteria and Aspergillus niger (A. niger) as a fungus. The microbial inoculates were prepared and the suspensions were adjusted to $10^{6}$ $\mathrm{CFU} / \mathrm{mL}$. After that, the tested samples (SA and QSA1, QSA3 and QSA6) and the reference drugs Ciprofloxacin, as a broad spectrum antibacterial drug, and Amphotericin B, as an antifungal one - were prepared. Then, two-fold serial dilution of the stock samples $(125,62.5,31.25,15.63,7.81,3.90,1.95$, $0.98,0.49$ and $0.24 \mu \mathrm{g} / \mathrm{mL}$ ) was performed in 96 well micro-plates, in which, $40 \mu \mathrm{L}$ of the growth medium brain heart infusion, $10 \mu \mathrm{L}$ of inoculums and $50 \mu \mathrm{L}$ of both tested sample solution and standard drugs were added. DMSO was used as a negative control. For antibacterial activity and antifungal activity assessment, the plates were incubated at $37{ }^{\circ} \mathrm{C}$ for 24 $\mathrm{h}$, and at $25^{\circ} \mathrm{C}$ for $48 \mathrm{~h}$, respectively. After the time of incubation, tetrazolium salt (2,3-bis[2-methyloxy-4nitro-5-sulfophenyl]-2H-tetrazolium-5-carboxanilide) (XTT), $40 \mu \mathrm{L}$, was added to the wells, then incubated in the dark at $37{ }^{\circ} \mathrm{C}$ for $1 \mathrm{~h}$. After incubation, the colorimetric change in the XTT reduction assay was measured at $492 \mathrm{~nm}$, using a micro-titer plate reader (Tecan Sunrise absorbance reader; Tecan UK, Reading, UK). Finally, the percentage of growth inhibition was determined according to Equation (1) below:

Inhibition percentage $=(1-$ Measured sample absorption / Control absorbance) X 100

The results are expressed as the mean value of three reproducible experiments.

\section{Cytotoxicity evaluation using viability assay}

For the cytotoxicity assay, in $100 \mu \mathrm{L}$ of growth medium, normal human lung fibroblast cells (WI-38 cell line) were seeded at a cell concentration of $1 \times 10^{4}$ cells per well in a 96-well plate. Serial doubling dilutions of the chemical compound tested were added to the convergent cell monolayers dispensed in the 96well, flat-bottomed microliter plates (Falcon, NJ, USA) with a multichannel pipette. For each test sample concentration, three wells were used, the control cells were incubated without a test sample, with or without DMSO. The little percentage of DMSO present in the wells (maximum $0.1 \%$ ) was found not to affect the experiment. The yield of viable cells was determined by the colorimetric method after incubation of the cells. All experiments were performed in triplicates and a calculation was made of the cell cytotoxic effect of each tested compound. The optical density was determined using the micro-plate reader (SunRise, TECAN, Inc, USA) to assess the number of viable cells and the viability percentage was calculated as $[(\mathrm{ODt} / \mathrm{ODc})] \times 100$ per cent, where ODt is the mean optical density of the wells treated with the sample, and ODc is the mean optical density of untreated cells. The cytotoxic concentration (CC50), the concentration needed to cause toxic effects in $50 \%$ of intact cells, was determined for each concentration from graphic plots of the dose response curve, using of Graphpad Prism (San Diego, CA. USA) software. ${ }^{34}$

\section{Measurements}

FTIR spectra of Quat, SA and QSA composites were acquired on a JR-Affinity ${ }^{-1}$ Shimadzu Fourier Transform Spectrophotometer, using $\mathrm{KBr}$ pellets within the wavenumber range of $4000-400 \mathrm{~cm}^{-1}$ at 25 ${ }^{\circ} \mathrm{C}$.

${ }^{1} \mathrm{H}-\mathrm{NMR}$ spectra of Quat, SA and QSA composites were analyzed by a Varian Mercury VX-300 NMR Spectrometer and the spectra were operated at 300 $\mathrm{MHz}$ in $\mathrm{D}_{2} \mathrm{O}$ as solvent.

$\mathrm{X}$-ray diffractograms of SA and QSA samples were recorded on an X-ray powder diffractometer (Philips Xpert MPD Pro), using Ni-filter and $\mathrm{CuK} \alpha$ radiation source $(50 \mathrm{kV} / 40 \mathrm{~mA})$. The relative intensity was recorded at a scan speed of 1 step $\mathrm{s}^{-1}$ in the scattering range $2 \theta$ from $5^{\circ}$ to $60^{\circ}$.

Surface morphology images of the tested samples were examined with SEM (Quanta 250 FEG). The freeze-dried samples were loaded on the surface of an aluminum SEM specimen holder and sputter coated with gold, before photographed.

\section{RESULTS AND DISCUSSION Characterization and 1 structure confirmation of QSA composites}

QSA composites were prepared by the reaction of sodium alginate with $N$-(3-chloro-2hydroxypropyl) trimethylammonium chloride at room temperature. It seemed that the quaternary alkyl moiety attacks the secondary $\mathrm{OH}$ groups, 
forming etherifying quaternized composite. The chemical structure of QSA composites was detected using FTIR and ${ }^{1} \mathrm{H}-\mathrm{NMR}$ tools, which provided information about the newly added functional groups, while the morphology and surface topology were clarified through SEM images. The inner structure and the changes in the alginate crystallinity upon quaternization were studied by XRD analysis. In addition, the reaction time was varied to investigate its effect on the percentage degree of quaternization, which increased significantly with increasing the reaction time up to $6 \mathrm{~h}$, as calculated from ${ }^{1} \mathrm{H}$ NMR analysis.

\section{Fourier transform infrared (FTIR) spectroscopy}

Figure 1 shows the FTIR spectra of SA, Quat188 and QSA6 (as representative example). The FTIR spectrum of SA presented the following common absorption bands: a broad band around $3435 \mathrm{~cm}^{-1}$ related to the hydrogen bonded $\mathrm{OH}$ groups, the absorption band at $2928 \mathrm{~cm}^{-1}$ referred to the stretching vibration of $-\mathrm{C}-\mathrm{H}$ bonds. Strong

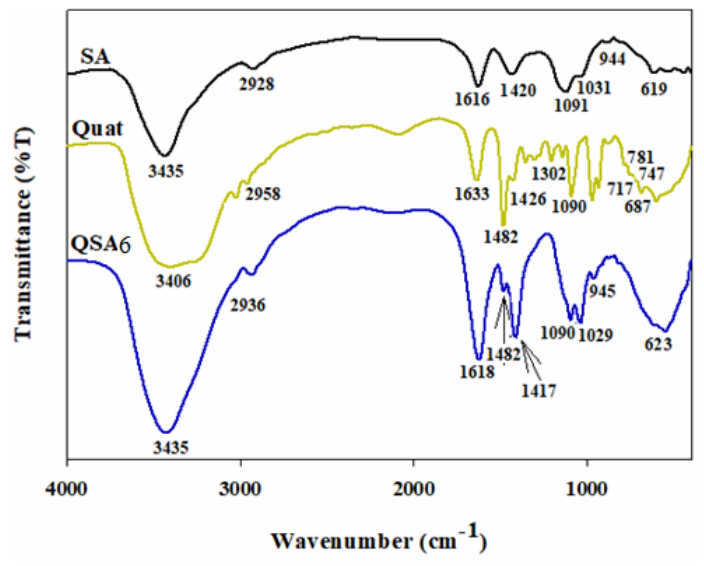

absorption bands appeared at 1616 and $1420 \mathrm{~cm}^{-1}$ attributed to asymmetrical and symmetrical vibrations of the carboxylate $-\mathrm{COO}^{-}$groups, respectively. The peaks at $1091, \overline{1031} \mathrm{~cm}^{-1}$ are assigned to the stretching vibration of -C-O-Cand $\mathrm{C}-\mathrm{OH}$ of the pyranose ring, respectively, the peak at $944 \mathrm{~cm}^{-1}$ corresponds to the overlapped $\mathrm{C}-\mathrm{C}-\mathrm{H}, \mathrm{C}-\mathrm{OH}$ (bending) and $\mathrm{C}-\mathrm{O}$ groups, the peak at $880 \mathrm{~cm}^{-1}$ is related to anomeric $\beta-\mathrm{C} 1-\mathrm{H}$ deformation. ${ }^{35,36}$

On the other hand, the spectrum of Quat displayed vibration bands at the following wavenumbers: $3406 \mathrm{~cm}^{-1}$ assigned to hydrogen bonded $\mathrm{OH}$ groups, $2958 \mathrm{~cm}^{-1}$ corresponding to $\mathrm{C}-\mathrm{H}$ stretching vibration, 1482 and $1426 \mathrm{~cm}^{-1}$ related to bending vibration of the methyl $\left(-\mathrm{CH}_{3}\right)$ and methylene $\left(-\mathrm{CH}_{2}-\right)$ groups, respectively. The observed peak at $1090 \mathrm{~cm}^{-1}$ is signed to $\mathrm{C}-\mathrm{O}$ bonds, the weak absorption band at $1302 \mathrm{~cm}^{-1}$ refers to $\mathrm{OH}$ bending vibration. The vibrations at 781,747 and $717 \mathrm{~cm}^{-1}$ are related to $\mathrm{N}-\mathrm{Cl}$ bonds, that at $687 \mathrm{~cm}^{-1}$ is attributed to out-of-plane $\mathrm{C}-\mathrm{H}$ bending. ${ }^{37}$
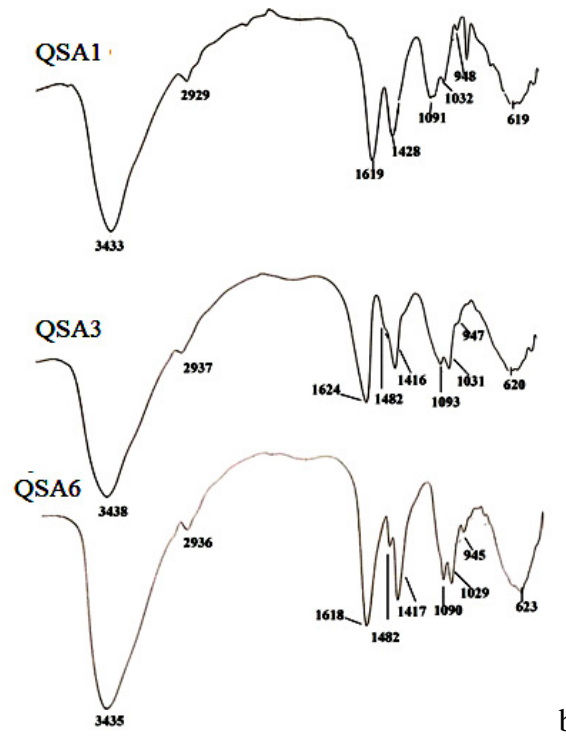

b)

Figure 1: FTIR spectra of (a) Quat, SA and QSA6, (b) QSA1, QSA3 and QSA6

The structure of quaternized sodium alginate QSA6 (as representative example) was significantly confirmed by its FTIR spectrum, which showed the following characteristic peaks: (1) the broad peak at $1090 \mathrm{~cm}^{-1}$ resulting from the additional ether linkage $-\mathrm{C}-\mathrm{O}-\mathrm{C}$ between alginate and the quaternary alkyl moiety; (2) the absence of peaks at 781,747 and $717 \mathrm{~cm}^{-1}$ corresponding to N-Cl bonds of Quat; (3) there was no change in the position of the peak at $1616 \mathrm{~cm}^{-1}$, corresponding to the carboxylate group of the = $\mathrm{COO}^{-}$, which confirmed the attack of the quaternized group on the secondary $\mathrm{OH}$ groups of alginate. Thus, the aforementioned data support the quaternization process and the formation of the QSA composite. 
It is worth mentioning that the degree of quaternization of sodium alginate increased with the increase in the reaction time, as evidenced by the FTIR spectra provided in Figure 1 (b). Accordingly, the FTIR spectra of QSA1, QSA3 and QSA6 showed a significant increase in the intensity of the peaks relating to the quaternized moiety around 1482, 1426 and $1090 \mathrm{~cm}^{-1}$, corresponding to the $-\mathrm{CH}_{3}$ group, $-\mathrm{CH}_{2}$ group and the etheric-C-O-C-bond, respectively, with the increase in the reaction time from QSA1 to QSA6.

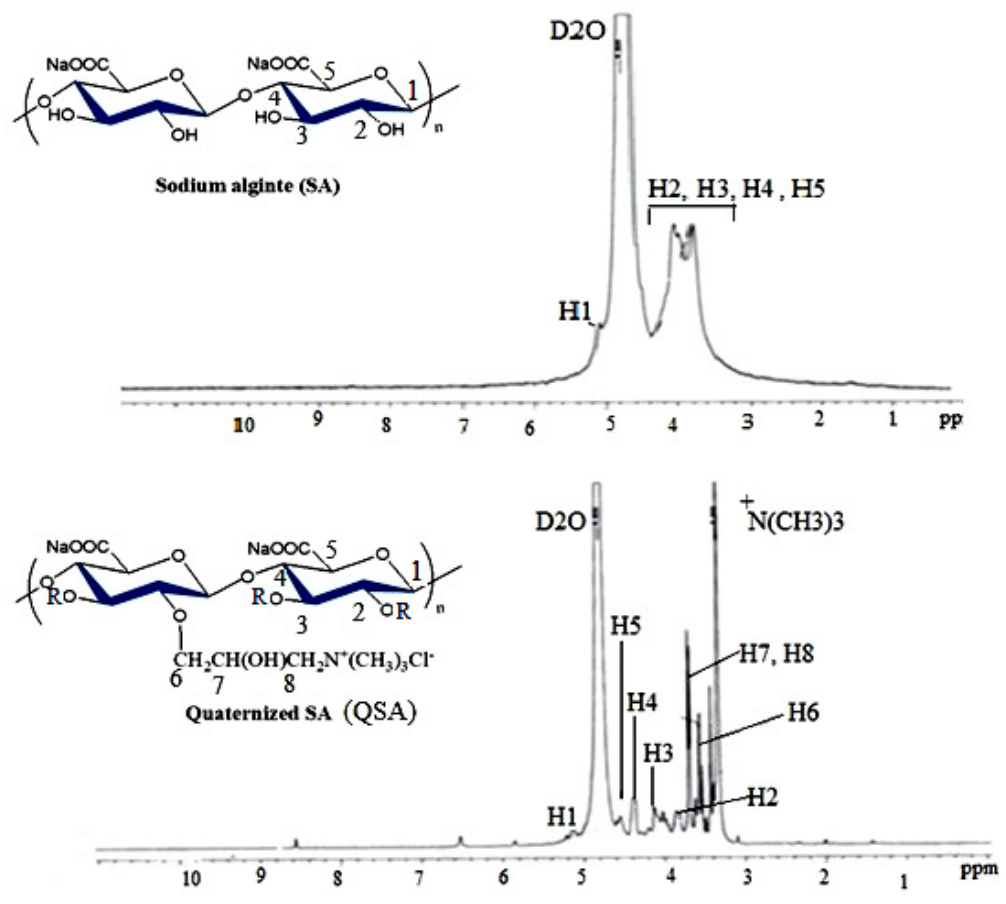

Figure 2: ${ }^{1} \mathrm{H}$-NMR spectra of SA and QSA6

\section{Proton nuclear magnetic resonance $\left({ }^{1} \mathrm{H}-\mathrm{NMR}\right)$}

Other evidence of the formation of the new QSA composite was elucidated from the ${ }^{1} \mathrm{H}-\mathrm{NMR}$ analysis. Figure 2 illustrates the ${ }^{1} \mathrm{H}-\mathrm{NMR}$ spectra of both SA and QSA6 (as representative example). Thus, the SA spectrum shows the following common signals: a multiplet at $\delta=3.8$ $4.1 \mathrm{ppm}$, corresponding to the protons of $\mathrm{C} 2, \mathrm{C} 3$, $\mathrm{C} 4$ and $\mathrm{C} 5(\mathrm{H} 2, \mathrm{H} 3, \mathrm{H} 4$ and $\mathrm{H} 5)$ of the pyranose ring; a singlet at $\delta=5.1 \mathrm{ppm}$, related to the anomeric proton $(\mathrm{H} 1)$ of the glucopyranose unit. ${ }^{38}$ Meanwhile, the spectrum of QSA6 displays the same signals of SA and, in addition, a sharp singlet at $\delta=3.4 \mathrm{ppm}$, assigned to the quaternary amino methyl groups $\left(\mathrm{N}^{+}\left(\mathrm{CH}_{3}\right)_{3}\right)$ and other signals at $\delta=3.5$ and $3.7 \mathrm{ppm}$, attributed to $-\mathrm{CH}$ and $\mathrm{CH}_{2}$ groups $(\mathrm{H} 6, \mathrm{H} 7$ and $\mathrm{H} 8)$ of the quaternary ammonium salt moiety, which confirm the achievement of the quaternization process. Furthermore, a sharp signal observed at $\delta=4.8$ ppm is related to the solvent $\mathrm{D}_{2} \mathrm{O}$.
Determination of the percentage degree of quaternization from ${ }^{1} \mathrm{H}-\mathrm{NMR}$ measurements

The quaternization of SA proceeded by binding of the quaternized alkyl moiety with the secondary $\mathrm{OH}$ of $\mathrm{SA}$ to produce the QSA composite. The percentage degree of SA quaternization (DQ\%) was measured kinetically at various time intervals $(1,3$ and $6 \mathrm{~h})$ in order to determine the optimal time that yielded a greater degree of quaternization. Based on the reaction time, three quaternized samples QSA1, QSA3 and QSA6 were prepared, and the DQ\% was determined after each reaction time from the integration under the proper signals in ${ }^{1} \mathrm{H}-\mathrm{NMR}$ spectra, according to the following equation 2 :

$\left.\mathrm{DQ} \%=\left(\left(\left[\mathrm{N}^{+}\left(\mathrm{CH}_{3}\right)_{3}\right]\right) /([\mathrm{H}])\right) \times 1 / 9\right) \times 100$

where $[\mathrm{N}+(\mathrm{CH} 3) 3]$ is an integral part of the trimethylamine group and $[\mathrm{H}]$ is an integral part of $\mathrm{C} 1$ protons of the pyranose ring (Fig. 3a). ${ }^{38}$ The results confirmed that the DQ\% increased as the 
reaction time increased. It was observed that the percentage of quaternization reached $63.8 \%$ after $1 \mathrm{~h}$ of the reaction, rose to $70.6 \%$ after $3 \mathrm{~h}$, and further increased to $85.0 \%$ after $6 \mathrm{~h}$ of reaction time. The correlation between DQ\% and the reaction time was depicted in (Fig. 3b). The data indicate that the reaction time is an important factor influencing the phase of quaternization.

\section{Powder X-ray diffraction (XRD)}

In order to show the changes in the inner structure of sodium alginate after incorporation of the quaternary ammonium moiety, the XRD diffraction patterns of SA and QSA composites were analyzed. Figure 4 illustrates the XRD pattern of alginate, displaying a crystalline structure shown by the two crystalline peaks at $2 \theta=13.7^{\circ}$ and $23.0^{\circ}, 39,40$ as a result of the large number of internal hydrogen bonding and the ordering of the chains. These crystalline peaks entirely disappeared after the quaternization process and were replaced by an amorphous structure clearly observed in the XRD patterns of all the QSA composites.

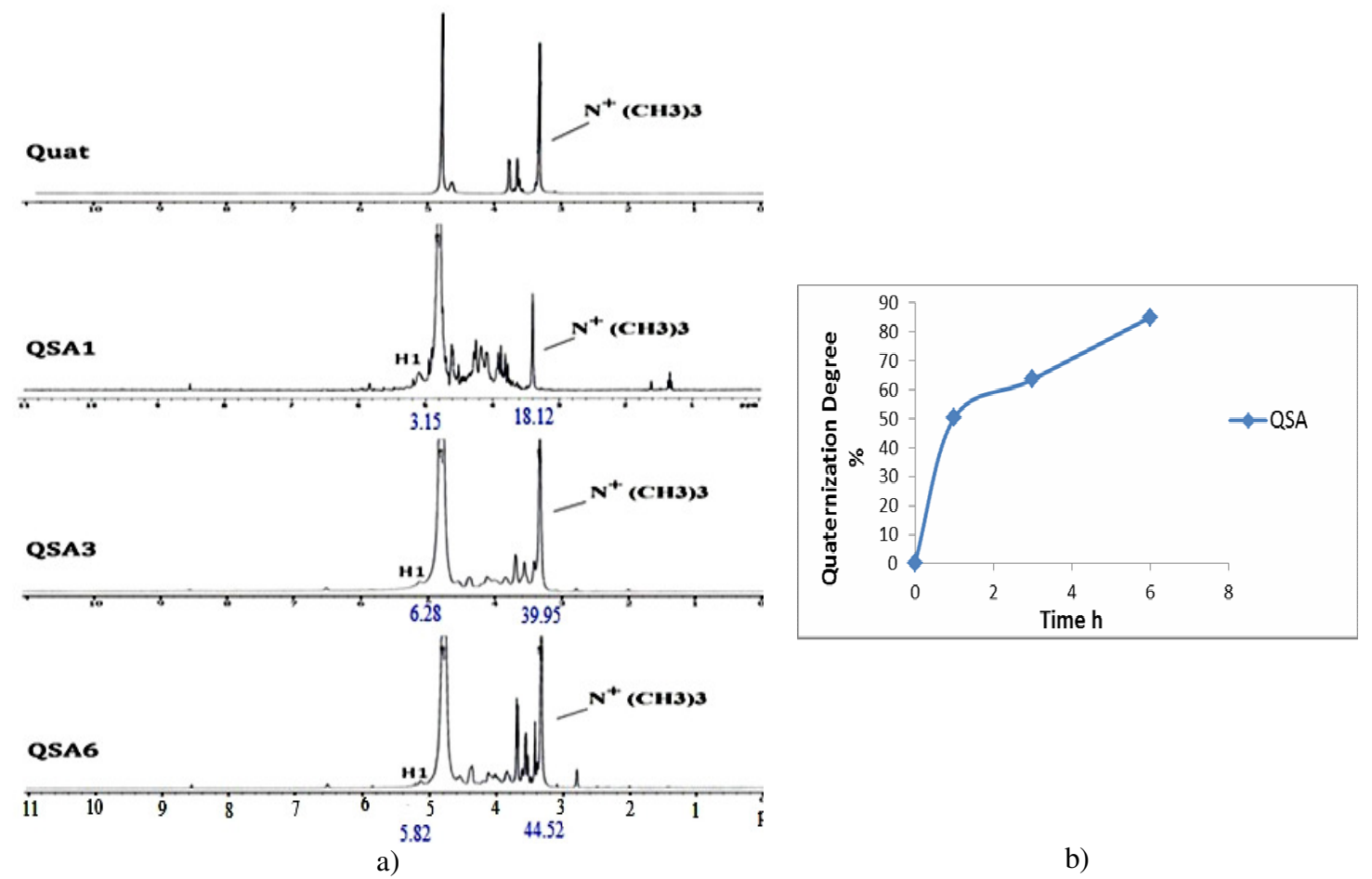

Figure 3: (a) Determination of quaternization degree at different time intervals;

(b) Evolution of quaternization degree over time

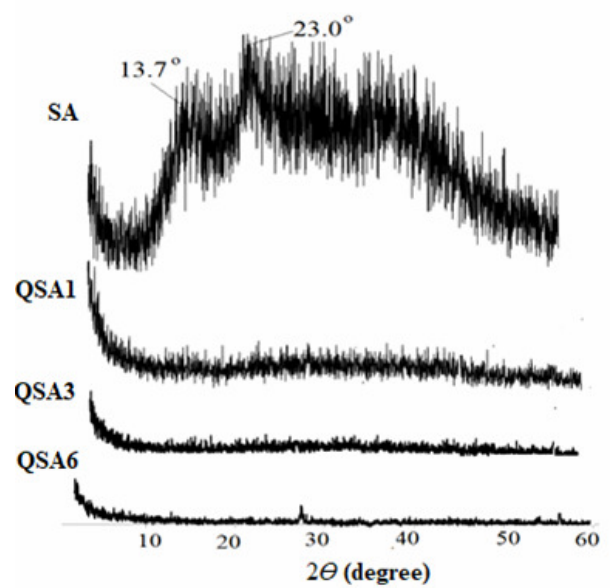

Figure 4: XRD patterns of SA and QSA1, QSA3 and QSA6 composites 
It seems that the incorporated quaternary ammonium moiety substantially breaks the intramolecular and intermolecular hydrogen bonds between the alginate chains, thus increasing the intermolecular distance between the neighboring chains, leading to a more open and amorphous structure. It became clear that, as the degree of quaternization rose, the amorphous fraction increased, depending on the time of the quaternization process.

\section{Scanning electron microscopy (SEM)}

Scanning electron microscopy was used to study the changes that occurred in SA surface morphology after the quaternization process. From the SEM images, the SA surface appears smooth, with a small amount of lumps due to the presence of -COO- groups, while QSA images show a rough surface, with a lot of conglomerates due to the quaternary ammonium moiety incorporated onto the SA backbone. The SEM images illustrate that the degree of agglomeration increased with increasing the degree of quaternization from QSA1 to QSA6, as shown in Figure 5.

\section{Antimicrobial activity of QSA composites}

XTT is a negatively charged, tetrazolium salt that turns orange when it is reduced to a soluble formazan dye. This extracellular reduction is carried out by electron transport across the plasma membrane of a living cell. The amount of XTT reduced is reflective of the cellular metabolic activity. The absorbance can be measured and compared to the absorbance of a control solution of untreated cells to determine if cellular metabolic activity has increased or decreased.
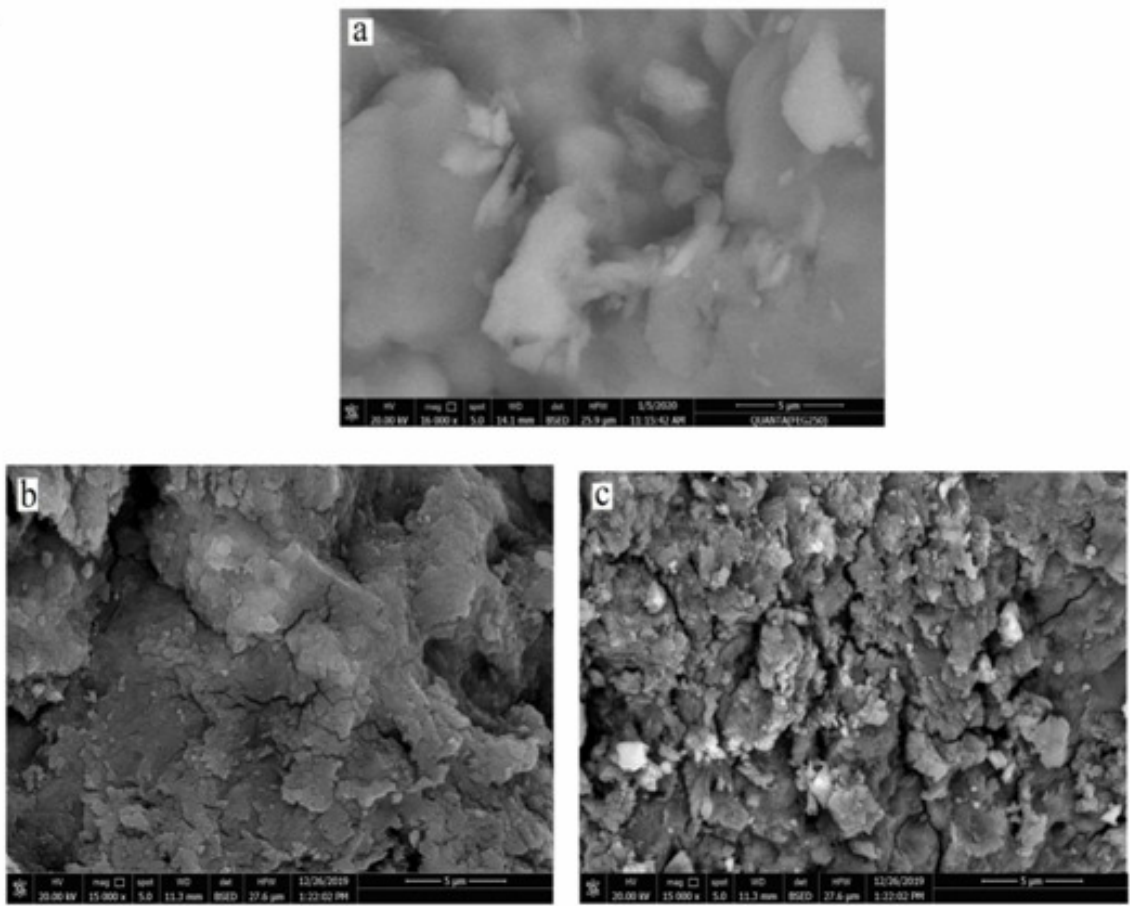

Figure 5: SEM images of (a) SA, (b) QSA1 and (c) QSA6, at 15000x magnification

For determining the antimicrobial activity of sodium alginate (SA) and QSA composites against four pathogenic microorganisms, including Staphylococcus aureus (S. aureus) as Gram-positive bacteria, Pseudomonas aeruginosa $(P$. aeruginosa) and Salmonella enteritidis (S. enteritidis) as Gram-negative bacteria and
Aspergillus niger (A. niger) as a fungus, the XTT assay proceeded by measuring the minimum inhibitory concentration values (MICs) of the tested samples that inhibited the growth of the microorganisms. Ciprofloxacin and Amphotericin $\mathrm{B}$ were used as conventional drugs for bacteria and fungi, respectively. 


\section{Antibacterial activity}

Figure 6 shows the antimicrobial activity of SA and QSA composites against both Grampositive and Gram-negative bacteria. The experimental data showed that SA did not have antimicrobial activity against the studied bacteria, there was no colorimetric shift of XTT, which is in agreement with the results of previously mentioned work, ${ }^{41}$ while QSA composites exhibited higher antibacterial activity towards the tested bacteria. It seems that the quaternized moiety (3-chloro-2-hydroxy propyl trimethylammonium chloride), significantly strengthened the antibacterial potency of sodium alginates. The higher antibacterial activity of QSA resulted from its easy penetration into the bacterial cytoplasm and the interaction with the negatively charged cell membrane, leading to disruption of the cell function and metabolic activity, as indicated by the XTT colorimetric shift. The three QSA composites exhibited inhibition potency for bacterial growth, as seen from their lower MIC values in Table 1. The data illustrate that the MIC values significantly decreased as the percentage of quaternization (DQ\%) increased from QSA1 (DQ\%, 63.8\%) to QSA6 (DQ\%, 85.0\%). This may be associated with the increasing density of the positively charged species $\left(\mathrm{N}^{+}\left(\mathrm{CH}_{3}\right)_{3}\right)$ in the polymeric matrix. This resulted in an increase in the electrostatic interaction with the negatively charged bacterial cell membrane, thereby retarding the growth of bacteria. From Table 1, the MIC values measured for QSA1, QSA3 and QSA6 ranged from 1.95 to $31.25 \mu \mathrm{g} / \mathrm{mL}$ against S. aureus, 0.98 to $7.8 \mu \mathrm{g} / \mathrm{mL}$ against $S$. enteritidis, and 7.81 to $62.5 \mu \mathrm{g} / \mathrm{mL}$ against $P$. aeruginosa, compared to the MIC values of 0.98 and 3.9 $\mu \mathrm{g} / \mathrm{mL}$ of the reference drug Ciprofloxacin against the same strains, respectively. Interestingly, the QSA6 sample (relative to QSA1, QSA3) exhibited the strongest antibacterial activity, very close and in many cases equal to that presented by the reference drug Ciprofloxacin, as inferred from their MIC values.

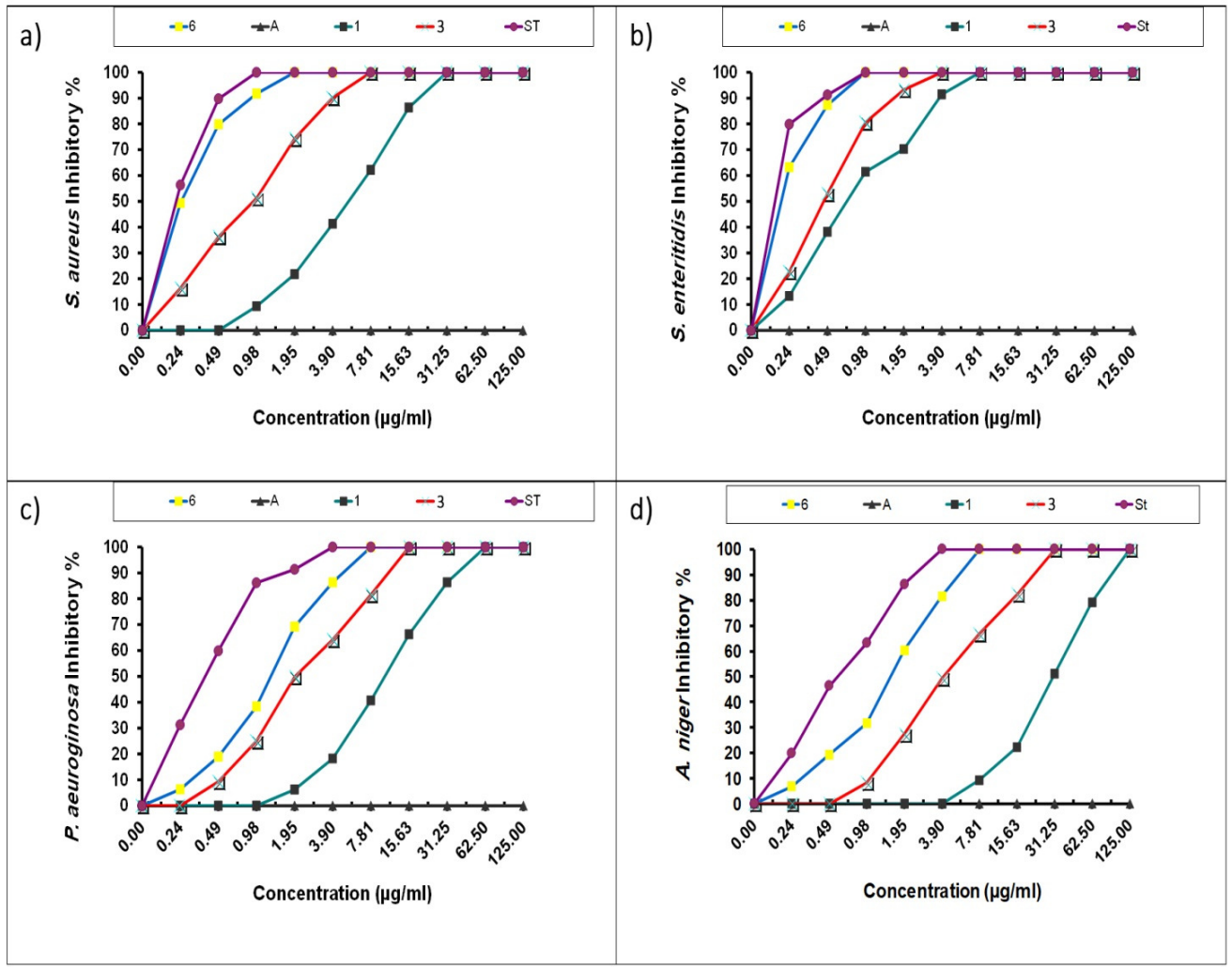

Figure 6: Microbial growth inhibition, \%, at various concentrations of alginate (A) and its three quaternized compounds at three different times: 1 (QSA1), 3 (QSA3) and 6 h (QSA6) against a) Staphylococcus aureus, b) Pseudomonas aeruginosa, c) Salmonella enteritidis and d) Aspergillus niger, compared with standards including Ciprofloxacin as a broad spectrum antibacterial and Amphotericin B as an antifungal. The results are expressed as the mean value of three reproducible experiments 
Table 1

Minimum inhibitory concentrations required to kill 50 (MIC 50) and 100\% (MIC) of the tested pathogens

\begin{tabular}{|c|c|c|c|c|c|c|c|c|c|c|}
\hline \multirow{2}{*}{ Pathogens } & \multicolumn{2}{|c|}{ SA } & \multicolumn{2}{|c|}{ QSA1 } & \multicolumn{2}{|c|}{ QSA3 } & \multicolumn{2}{|c|}{ QSA6 } & \multicolumn{2}{|c|}{ ST } \\
\hline & MIC & MIC 50 & MIC & MIC 50 & MIC & MIC 50 & MIC & MIC 50 & MIC & MIC 50 \\
\hline Gram-positive bacterium & & & & & & & & & \multicolumn{2}{|c|}{ Ciprofloxacin } \\
\hline $\begin{array}{l}\text { Staphylococcus aureus } \\
\text { ATCC } 25923\end{array}$ & NA & NA & 31.25 & 5.5 & 7.81 & 0.94 & 1.95 & 0.25 & 0.98 & 0.24 \\
\hline Gram-negative bacteria & & & & & & & & & \multicolumn{2}{|c|}{ Ciprofloxacin } \\
\hline $\begin{array}{l}\text { Salmonella enteritidis } \\
\text { ATCC } 13076\end{array}$ & NA & NA & 7.81 & 0.74 & 3.9 & 0.46 & 0.98 & 0.24 & 0.98 & 0.24 \\
\hline $\begin{array}{l}\text { Pseudomonas aeruginosa } \\
\text { ATCC } 15692\end{array}$ & NA & NA & 62.5 & 10.67 & 15.63 & 1.97 & 7.81 & 1.35 & 3.9 & 0.31 \\
\hline Fungus & & & & & & & & & \multicolumn{2}{|c|}{ Amphotericin B } \\
\hline $\begin{array}{l}\text { Aspergillus niger } \\
\text { ATCC } 9142\end{array}$ & NA & NA & 125 & 30.6 & 31.25 & 4.0 & 7.81 & 1.6 & 3.9 & 0.52 \\
\hline
\end{tabular}

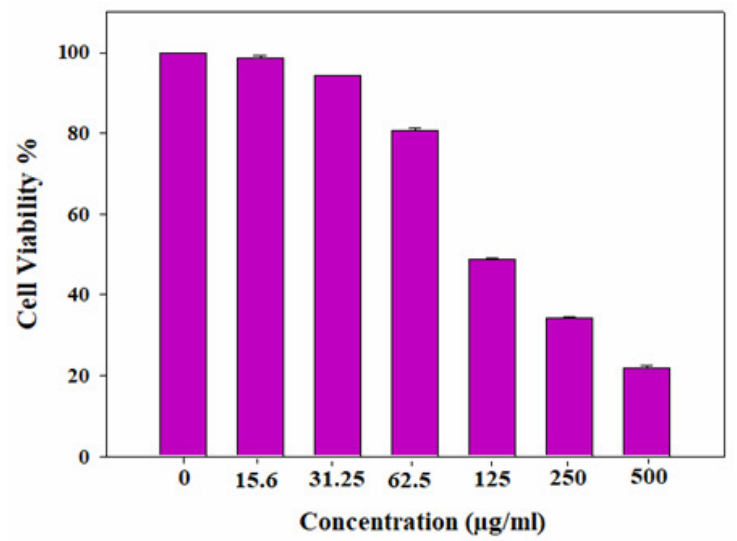

Figure 7: Cytotoxic effect of different concentrations of QSA6 composite on the viability of human lung fibroblast cells 
They displayed MIC vales equal to 1.95 , 0.98 and $7.81 \mu \mathrm{g} / \mathrm{mL}$ against the tested bacteria $S$. aureus, $S$. enteritidis and $P$. aeruginosa, compared to $0.98,0.98$ and $3.9 \mu \mathrm{g} / \mathrm{mL}$ against the same bacterial strains, respectively. Although Gram-positive and Gram-negative bacteria have different cell wall structure ${ }^{19}$ the QSA composites showed stronger inhibition activity on both of them. This might be due to the presence of both hydrophilic and hydrophobic species in the QSA chains, which promote the penetration of the samples into the bacterial cells, leading to cell permeability disruption, in addition to binding with the cytoplasm DNA, preventing the formation of RNA, thus causing death in bacteria. ${ }^{42,43}$

\section{Antifungal activity}

The antifungal experimental data clarified that SA did not have any inhibition activity on the growth of the tested fungus A. niger, while all the QSA composites exhibited higher potency in inhibition of the fungus growth, as shown in Figure 6. The measured MIC values of the QSA composites resulting in $100 \%$ inhibition ranged from 7.81 to $125 \mu \mathrm{g} / \mathrm{mL}$, as the inhibition efficiency increased by increasing the DQ\% from QSA1 to QSA6. The hypothesized mechanism for the antifungal activity of QSA is based on: (1) the electrostatic force interactions between the cationic groups on QSA chains and the electronegative charges on the fungus surfaces, leading to leakage of intracellular electrolytes and proteinaceous constituents; (2) QSA can penetrate inside the hyphae of $A$. niger and intervene with the activities of the enzyme that are responsible for fungus growth, similarly to the findings of previous work reported on a chitosan derivative. $^{44}$

\section{Estimation of cytotoxicity of QSA composite}

The cytotoxicity exhibited by QSA6 (as representative example) on normal human lung fibroblast cells (WI-38 cell line) was investigated utilizing different concentrations of the sample ranging between 0 and 500 $\mu \mathrm{g} / \mathrm{mL}$, as shown in Figure 7. WI-38 cell viability was not affected by the QSA6 sample at concentrations below $15.6 \mu \mathrm{g} / \mathrm{mL}$ - no inhibitory action was observed in this sample below this concentration. The cytotoxicity gradually increased by increasing sample concentration up to $500 \mu \mathrm{g} / \mathrm{mL}$. Moreover, the concentration of QSA6 that caused a toxic impact in half of the intact cells (IC50) was $122 \mu \mathrm{g} / \mathrm{mL}$. From Figure 6, the QSA6 sample showed strong activity against the tested bacteria and fungi, with minimum inhibitory concentration (MIC) values (ranging from 0.98 to $7.81 \mu \mathrm{g} / \mathrm{mL}$ ), i.e. smaller than the cytotoxic concentration $(15.6 \mu \mathrm{g} / \mathrm{mL})$. This showed that the use of such materials on the human cells is safe and they could be recommended as antimicrobial agents in biomedical and food applications.

\section{CONCLUSION}

Quaternization of sodium alginate (SA) proceeded in alkaline medium using 3-chloro2-hydroxypropyltrimethylammonium chloride (Quat 188) in different time intervals: 1, 3, and $6 \mathrm{~h}$, to prepare quaternized sodium alginate (QSA) composites with high degree of quaternization. The grafting of the quaternized moiety onto SA through chemical covalent bond was elucidated via FTIR, H-NMR, XRD, SEM, and TGA techniques. Three different QSAs were successfully fabricated with various degrees of quaternization (DQ)\%, calculated from H-NMR images, as $63.8 \%$ (QSA1), 70.6\% (QSA3), and 85.0\% (QSA6). Moreover, the data of antimicrobial activity for the three different QSA composites and unmodified SA against four pathogenic foodborne pathogens: Staphylococcus aureus, Pseudomonas aeruginosa, Salmonella enteritidis and Aspergillus niger, exhibited microbial attack against SA from all the microorganisms, while the three prepared QSAs showed high broad spectrum antimicrobial activity against the four examined microorganisms. Also, the results illustrated the sustained increased antimicrobial activity with a boost in DQ\%. Thus, the QSA6 sample demonstrated the highest inhibition of all the microorganisms' growth, and its MIC (100\% inhibition) values were listed as $0.98,1.95$ and $7.81 \mu \mathrm{g} / \mathrm{mL}$ against bacteria: $S$. enteritidis, $S$. aureus and $P$. aeruginosa, respectively, as well as highly effective activity against $A$. niger fungus as $7.81 \mu \mathrm{g} / \mathrm{mL}$. Additionally, the cytotoxic activity of QSA6 was investigated against normal human cells and the data confirmed that the prepared grafted composites can be used as safe and promising antimicrobial agents in medicine and food industries. 


\section{REFERENCES}

A Abbasi, Z. Emam-Djomeh, M. A. E. Mousavi and D. Davoodi, Food Chem., 143, 379 (2014), https://doi.org/10.1016/j.foodchem.2013.08.018 2 H. Jolink, R. de Boer, P. Hombrink, R. E. Jonkers, J. T. van Dissel et al., J. Infect., 74, 81 (2017), https://doi.org/10.1016/j.jinf.2016.10.010

3 N. A. Mohamed, N. A. Abd El-Ghany, Mona M. Fahmy and M. M. Abdel-Aziz, Polym. Adv. Technol., 1 (2020), https://doi.org/10.1002/pat.5179

4 Y. Chang, H. Yoon, D. H. Kang, P. S. Chang and S. Ryu, Int. J. Food Microbiol., 244, 19 (2017), https://doi.org/10.1016/j.ijfoodmicro.2016.12.007

M. H. Abu Elella, M. Sabaa, D. H. Hanna, M. M. Abdel-Aziz and R. R. Mohamed, J. Drug. Deliv. Sci. Technol., 57, $101673 \quad$ (2020), https://doi.org/10.1016/j.jddst.2020.101673

6 H. Xing, M. Lu, T. Yang, H. Liu, Y. Sun et al., Acta Biomater., 86, $15 \quad$ (2019), https://doi.org/10.1016/j.actbio.2018.12.041

7 A. Muñoz-Bonilla, C. Echeverria, A. Sonseca, M. P. Arrieta and M. Fernández-García, Materials, 12, 641

(2019),

https://doi.org/10.3390/ma12040641

8 M. M. Konai, B. Bhattacharjee, S. Ghosh and J. Haldar, Biomacromolecules, 19, 1888 (2018), https://doi.org/10.1021/acs.biomac.8b00458

9 C. Ergene, K. Yasuhara and E. F. Palermo, Polym. Chem., 9, $2407 \quad$ (2018), https://doi.org/10.1039/C8PY00012C

10 M. Mujtaba, R. E. Morsi, G. Kerch, M. Z. Elsabee, M. Kaya et al., Int. J. Biol. Macromol., 121, 889 (2019),

https://doi.org/10.1016/j.ijbiomac.2018.10.109

11 C. Vasile, Materials, 11, 1834 (2018), https://doi.org/10.3390/ma11101834

12 P. Yadav, H. Yadav, V. G. Shah, G. Shah and G. Dhaka, J. Clin. Diagn., 9, ZE21 (2015), https://doi.org/10.7860/JCDR/2015/13907.6565

13 A. S. Veiga and J. P. Schneider, J. Pept. Sci., 100, 637 (2013), https://doi.org/10.1002/bip.22412

14 D. S. Cha and M. S. Chinnan, Crit. Rev. Food Sci. Nutr., 44, $223 \quad$ (2004), https://doi.org/10.1080/10408690490464276

15 M. Shahid and F. Mohammad, Ind. Eng. Chem., 52, 5245 (2013), https://doi.org/10.1021/ie303627x

16 M. U. Sankar, S. Aigal, S. M. Maliyekkal, A. Chaudhary, A. A. Kumar et al., PNAS, 110, 8459 (2013), https://doi.org/10.1073/pnas.1220222110

17 S. Kondaveeti, P. V. de Assis Bueno, A. M. Carmona-Ribeiro, F. Esposito, N. Lincopan et al., Carbohyd. Polym., 186, $159 \quad$ (2018), https://doi.org/10.1016/j.carbpol.2018.01.044

18 O. Jeon, D. S. Alt, S. M. Ahmed and E. Alsberg, Biomaterials, 33, $3503 \quad$ (2012), https://doi.org/10.1016/j.biomaterials.2012.01.041

19 N. A. Abd El-Ghany, M. S. A. Aziz, M. M. Abdel-Aziz and Z. Mahmoud, Int. J. Biol. Macromol., $\quad$ 134, $912 \quad$ (2019), https://doi.org/10.1016/j.ijbiomac.2019.05.078
20 E. Obłąk, A. Piecuch, J. Rewak-Soroczyńska and E. Paluch, Appl. Microbiol. Biotechnol., 103, 625 (2019), https://doi.org/10.1007/s00253-0189523-2

21 M. E. Fait, L. Bakas, G. L. Garrote, S. R. Morcelle and M. C. Saparrat, Appl. Microbiol. Biotechnol., $\quad$ 103, $97 \quad$ (2019), https://doi.org/10.1007/s00253-018-9467-6

22 P. Makvandi, R. Jamaledin, M. Jabbari, N. Nikfarjam and A. Borzacchiello, Dent. Mater., 34, 851

https://doi.org/10.1016/j.dental.2018.03.014

23 I. Mulder, J. Siemens, V. Sentek, W. Amelung, K. Smalla et al., Rev. Environ. Sci. Biotechnol., 17, 159 (2018), https://doi.org/10.1007/s11157-0179457-7

${ }^{24}$ H. Tan, R. Ma, C. Lin, Z. Liu and T. Tang, Int. J. Mol. Sci., 14, $1854 \quad$ (2013), https://doi.org/10.3390/ijms14011854

${ }^{25}$ Y. Song, Y. Sun, X. Zhang, J. Zhou and L. Zhang, Biomacromolecules, 9, 2259 (2008), https://doi.org/10.1021/bm800429a

26 N. A. Abd El-Ghany and Z. M. Mahmoud, Polym. Bull., 1 (2020), https://doi.org/10.1007/s00289-020-03417-8

27 R. C. Goy, S. T. Morais and O. B. Assis, Rev. Bras. Farmacogn., 26, $122 \quad$ (2016), https://doi.org/10.1016/j.bjp.2015.09.010

28 D. Hu, T. Qiang and L. Wang, Wound Med., 16, 15

https://doi.org/10.1016/j.wndm.2016.12.003

${ }^{29}$ S. Geresh and R. Dawadi, Carbohyd. Polym., 43, 75 (2000), https://doi.org/10.1016/S01448617(99)00194-0

30 Y. Zhang, Y. Zhou and C. Liu, Polym. Bull., 71, 1909 (2014), https://doi.org/10.1007/s00289-0141163-9

31 B. Liu, J. Luo, X. Wang, J. Lu, H. Deng et al., J. Biomater. Sci. Polym., 24, 589 (2013), https://doi.org/10.1080/09205063.2012.701160

32 Y. Wang and W. Xie, Carbohyd. Polym., 80, 1172

(2010), https://doi.org/10.1016/j.carbpol.2010.01.042

33 M. M. Tunney, G. Ramage, T. R. Field, T. F. Moriarty and D. G. Storey, AAC, 48, 1879 (2004), https://doi.org/10.1128/AAC.48.5.1879-1881.2004

34 H. Itagaki, S. Hagino, S. Kato, T. Kobayashi and M. Umeda, Toxicol. In Vitro, 5, 139 (1991), https://doi.org/10.1016/0887-2333(91)90034-B

35 H. Daemi and M. Barikani, Sci. Iran., 19, 2023 (2012), https://doi.org/10.1016/j.scient.2012.10.005 36 M. Taha, K. Aiedeh, Y. Al-Hiari and H. AlKhatib, Pharmazie, 60, $736 \quad$ (2005), https://www.ingentaconnect.com/content/govi/phar maz/2005/00000060/00000010/art00003\#expand/c ollapse

37 O. Kostyk, O. Budishevska, V. Vostres, Z. Nadashkevych and S. Voronov, Catalysis, 150, 1 (2019), https://doi.org/10.32434/0321-4095-2019127-6-113-120 


\section{MAHMOUD H. ABU ELELLA et al.}

38 L. Marci, M. C. Meloni, A. M. Maccioni, C. Sinico, F. Lai et al., Chem. Select., 1, 669 (2016), https://doi.org/10.1002/slct.201600145

39 Q. Wang, X. Hu, Y. Du and J. F. Kennedy, Carbohyd. Polym., 82, $842 \quad$ (2010), https://doi.org/10.1016/j.carbpol.2010.06.004

40 G. Yang, L. Zhang, T. Peng and W. Zhong, J. Membrane Sci., 175, 53 (2000), https://doi.org/10.1016/S0376-7388(00)00407-5

${ }^{41}$ H. E. Salama, M. S. A. Aziz and M. W. Sabaa, Int. J. Biol. Macromol., 116, 443 (2018), https://doi.org/10.1016/j.ijbiomac.2018.04.183
42 T. Xu, M. Xin, M. Li, H. Huang, S. Zhou et al., Carbohyd. Res., 346, $2445 \quad$ (2011), https://doi.org/10.1016/j.carres.2011.08.002

43 M. H. Abu Elella, E S. Goda, H. M. Abdallah, A. E. Shalan, H. Gamal et al., Int. J. Biol. Macromol., 167, $1113 \quad$ (2021), https://doi.org/10.1016/j.ijbiomac.2020.11.065

44 Z. Guo, R. Xing, S. Liu, Z. Zhong, X. Ji et al., Carbohyd. Polym., 71, $694 \quad$ (2008), https://doi.org/10.1016/j.carbpol.2007.10.021 